\title{
Transformative Performing Arts and Mentorship Pedagogy: Nurturing Developmental Relationships in a Multidisciplinary Dance Theatre Program for Youth
}

\author{
Kevin M. Kane \\ Correspondence: Kevin M. Kane, Claremont Graduate University, University of California, Los Angeles, The Flourish \\ Foundation, 6224 Poppy Peak Dr., Los Angeles, CA 90042, USA.
}

\author{
Received: January 9, 2014 Accepted: January 30, 2014 Online Published: March 18, 2014 \\ doi:10.11114/jets.v2i2.316 URL: http://dx.doi.org/10.11114/jets.v2i2.316
}

\begin{abstract}
A multidisciplinary dance and theatre arts program geared for high school-aged youth can result in both short-term and the long-term outcomes for its students if it seeks to offer a life-changing peak experience as part of the arts training and performance process. By integrating a combination of dance, movement, theater, music, creative and reflective writing, as well as identity exploration and creative collaborations, performing arts programs can provide participants an experience that is truly transformative. In particular, such a program can help initiate and support meaningful mentoring and developmental relationships. A summer performing arts program set at a university site is an ideal opportunity to implement a sequence of strategic creative and social activities that offer high school youth daily activities that can establish a foundation for these significant relationships to emerge. By including college-aged program counselors who attended the program when they were in high school, acting as "step-ahead" peers, a program model such as this one provides potent possibilities for burgeoning leaders and mentors to emerge and meaningful relationships to take hold. Furthermore, the performance material generated in such a program can directly represent the personal evolutions of the students and the developmental relationships that are originated throughout the program's creative and social processes. This article uses the UCLA Summer High School Dance Theater Intensive program as a case study of a progressive, multidisciplinary, summer performing arts program that positions the initiation of developmental relationships as one of its core values.
\end{abstract}

Keywords: transformational and transformative pedagogy, youth mentorship, developmental relationships, multidisciplinary dance, multidisciplinary arts, peak experience, flow, generativity, step-ahead peer, transformational learning, progressive education, threshold theories, flourishing.

\section{Introduction}

An adolescent's path is characterized by alternatingly smooth and treacherous twists and turns. This intricate journey raises the question: How does anyone get from here to there ... in life, in higher education, in a career, and in the arts? Dance and movement arts practices that use a progressive pedagogical approach, characterized by transformative pedagogy and collaborative creative methods, offer unique mentoring possibilities that can assist youth as they navigate this journey and imagine possibilities in all these realms. This article presents a case study of how the UCLA High School Dance Theater Intensive program, a summer immersion program for high school youth in multidisciplinary dance and theatre, one that seeks to be a peak experience for its participants, uses a series of progressive methods and processes. In doing so, it creates and makes use of a network of expert intercultural faculty and college-aged "step-ahead" peers to facilitate the extension of transformational moments into long-term mentoring outcomes.

In dance, as in life, students regularly face the test of settling upon the most impactful and effective path to take. Some barriers are, on the surface, relatively easy to manage but others offer a greater challenges and more confusing encounters. According to influential movement theorist Rudolf Laban, "man moves in order to satisfy a need," (Newlove 1993, p. 11) and, therefore, participating in the "dance of life" (p. 16) involves not only knowing where we are going, but also exploring how we are getting there and, why. Likewise, exploring this grand choreography (our life's ongoing composition) means becoming mindful of the effort and energy we are using throughout our many passages. Ultimately, being able to determine and devise the nature and qualities of our interactions and relationships can help us achieve both operational and aspirational movement patterns. Understanding movement in this way can help all of us to identify and reach our goals, both artistically and in life. 
Connecting dance and movement practices with life practices is not too far-fetched an exercise. Dance scholar Miriam Giguere (2014) reminds us that the study and practice of dance is, "not merely learning new ways to move... it is also about embarking on a personal journey to explore and reflect the changes in yourself and in the world around you" ( $p$. viii). For dancers and movement performers, the practice of dancing, and making dances, offers countless opportunities and liberations but also presents a complicated landscape not always easy to negotiate and master. Certainly, dance and movement arts offer its practitioners an opportunity to develop physical dexterity, balance, and flexibility, and an overall sense of physical (and emotional, psychological) well being but, at the same time, dance performers are always exploring problematical collaborations with space and with time that very often involves forming alliances and relationships with other bodies. As such, the dancers' journeys are filled with both obstructions and possibilities, both always in the distance; there is always a hurdle to surmount or a surprising pathway to discover. There are often many choices when coordinating such elements though none without potential risks, missteps, or gambles.

To this end, student dancers learn to use a variety of strategies and intelligences to negotiate these complicated physical engagements and face down a seemingly endless array of possible transitions and changeovers, one after the other. They may follow prescribed pathways in set choreographies or creative blueprints previously established by an "authority" figure (the choreographer, coach, or director), or they might use their own creative instincts to move around, over, under, and beyond. Some moments might be set in stone, others more improvisational or flexible. In these journeys, dance and movement practices function as powerful facilitators; they can help youth learn how to gracefully and effectively journey through obstacles and take full advantage of life's opportunities. Dance and movement practices help students practice managing the trickiest of life transitions. Once the complication at hand has been handled, dancers can achieve a sense of momentum that simultaneously connects them to the past, situates them in the present, and directs them towards the future.

Later in the practice, these complications and transitions, and the ability to take them on and move past them, seem to arise and befall with regularity. In motion, the dancing body, especially those that achieve flow, suggests a dynamic mix of physical, intellectual, emotional, spiritual, and creative skills that seem to be a spontaneous expression of flexibility, potency, and autonomy, like a river flowing. According to positive psychologist Mihály Csíkszentmihályi (2008), during times of flow, people typically experience deep enjoyment, creativity, and a total involvement with life. In the very best of these "optimal" moments and experiences, Csíkszentmihályi describes how, "everything we experience - joy or pain, interest or boredom - is represented in the mind as information. If we are able to control this information, we can decide what our lives will be like" (p. 6). With such an approach to life, Csíkszentmihályi proposes that we feel, "in control of our actions" and "masters of our own fate" (2008, p. 3). Dance and movement arts, presented with a clear multidisciplinary mindset and learned and practiced (and enabled) in highly immersive and motivating sites, can help students achieve such exhilaration and empowerment.

Also, in life as in dance, the development of talents and competencies, along with a full sense of possibility, rarely develop in isolation. Psychologist and youth mentorship researcher Jean E. Rhodes (2002) concurs that by creating "special bonds of mutual commitment, respect, identification, and loyalty," (p. 4), youth workers are primed to help facilitate "the youth's transition into adulthood" (p. 4). Rhodes understands that most young people require assistance to understand the choices and options available to them. Youth, especially late adolescents, need positive partnerships - or "powerful relationships with nonfamily adults" (Rhodes 2002, p. 3) - to help them figure out how to imagine the possibilities, believe in themselves enough to try, and to plan their next moves. Youth require guidance and reassurances as they take in fresh ideas or grapple with innovative ways of doing something familiar. Youth require positive messages that encourage them to rebound from setbacks and doubts. Youth are often in search of mentors, very often non-family members, who can guide and support them as they attempt to direct (and even redirect) their life trajectories. These engagements and interventions can be crucial in assisting young people to approach important life milestones and inevitable personal evolutions; these are all assistances that a committed mentor can offer a willing teenager.

Similarly, a mentoring approach to learning dance, movement and theatre arts, and the performing arts can offer youth multiple meanings and countless rewards regarding what it means to be an artist and how to use the arts as a tool for expression, inspiration, and activism. It can provide an intergenerational connection between teachers and students, artistic experts and novices, advanced students and beginners, all of which can help students know those who came before them in the practice, and prepare them for being able to help those who will follow them as dance and performance students. Such connectivity can thereby extend the lineage of care, direction, momentum, and reinforcement. Of course, this description sounds as much like a dance as it describes real-life acts of generosity and connection whereby an older partner helps to make sense of some of life's most complex passages: adolescence into adulthood, high school into college, or home into away-from-home.

Mentoring partnerships and solid social networks for youth that are formulated in dance sites and other performing arts settings are likely to occur organically, at least superficially, merely by bringing older and younger dancers into the same space. However, these relationships are primed for a deeper effect when they are founded within a comprehensive 
arts program that is, at least somewhat, informed and inspired by $20^{\text {th }}$ century educational reformer John Dewey and his principals of progressive education $(1897,1902,1916)$. Dewey's famous educational manifestos call for a liberatory teaching practice that encourages deep reflection and dialogue as part of the practice. Responding to the progressive education standards, progressive teaching is characterized by meaningful exchanges and imaginative interfaces between students and teachers. Such proposals are still relevant, especially in the arts. Dewey's manifestos seek to offer students personal and academic (and, in this case, artistic) guidance that goes beyond merely training youth in traditional ways. In dance and the arts, it is a teaching pedagogy (bordering on a mentorship model) that recognizes and responds to the whole child, rather than just the dancing child.

Such an educational outlook can help produce students who are both scholarly artists and creative scholars, and, as such, infinitely capable of communicating initiative, self-expression, intelligence, and optimism. Progressive education scholars Simpson, Jackson, and Aycock (2005) concur that, "if we are going to positively influence children and youth as maturing, whole people, we will be called on to touch more than their intellectual development; for example, we will need to give attention to their social, emotional, ethical, and physical growth" (p. 4). Dance and multidisciplinary arts practices that are geared towards high school-aged youth, grounded in such values and motivated by these goals, are particularly aligned with such progressive educational ideals as pioneered by Dewey. It is an ideal opportunity and a prime site to utilize progressive methods that can connect youth to dance and the arts, help integrate and transect dance artistry to their larger life goals, and, simultaneously, initiate and coordinate mentoring relationships that can support and motivate these youth into the future.

For student artists, those just starting out and those who have been dancing and performing for several or many years (both formally and informally, in both traditional and non-traditional settings), understanding the ways that arts practices and life practices can correlate and refer to one another can be a distinct advantage in the formation of meaningful mentorships. The performing arts can serve as the ideal setting for such realizations to be made and activated. It is also a prime opportunity to inspire and embolden multiple talents and modes of creative expressions, all of which can provide confidence and dexterity as people and artists. By integrating a combination of dance, movement, theater, music, creative and reflective writing, as well as identity exploration and creative collaborations, performing arts programs can provide participants an experience that is truly transformative, and by offering mentors to help students see their way into, through, and beyond the actual experience, programs can better ensure that these benefits have an ongoing, even long-term, impact.

In a progressive multidisciplinary performing arts practice, an educational and creative process that is influenced by student interest and "where tradition alone does not rule but the best of the past is leavened with the discoveries of today" (Hayes 2007, p. xiv), students have an immediate opportunity to be satisfied through the, "application of knowledge gained and correlation between different subjects" (Hayes 2007, p. xiii). By having direct and indirect contact with other artistic practices, ideas, and activities, in an intercultural and intergenerational site where teachers are committed guides helping all to use various sources of information and ways of learning, the students are offered a peak experience. It is an opportunity for personal growth to occur, collective solidarity to develop, and for meaningful ongoing friendships and mentorships to form. The sequence of creative, artistic, and psycho-social activities in a progressive arts site, all of which emphasize critical concentration as well as a commitment to joy and generosity, can produce great openness and liberation, and, ultimately, great pride in both the students and their teacher coaches. Such an experience can be transformational for all involved.

Performing arts practices that commit to key values of a progressive education, most especially those programs that are able to create a climate of inclusivity and diversity, can bring people of difference, including intergenerational combinations, into the same space at the same time, with everyone participating in practices and activities that inspire them. This particularly engaged performing arts setting can readily link youth with prospective mentors who are equally engaged in the artistic practice. Such an approach to learning dance and theatre arts lessens the possibilities for extreme competition, cliques, or the escalation of oppositional energies (in any form) to define the experience but instead, as "threshold" transformation theorist AnaLouise Keating (2013) describes, this method increases the possibility to "create transformational alliances" (p. 7) that can help each participant, "acquire additional, potentially transformative perspectives, different ways to understand ourselves, our circumstances, and our world" (p. 13). The results of such an experiment can be beneficial in a reciprocal and shared way; the results can be motivated and sustained by optimism - a profound discovery that declares: yes, I can dance, I can be an artist, I can go to college, I can graduate, I can get through this tough time... I can!

A shared passion between mentors and students - in this case, engaging in acts of creative expression, multidisciplinary artistic skill, and progressive social cohesion - can be a jumping off point for an immediate mutual connection. Then, throughout the arts training, art-making, and social bonding activities of such a progressive practice, this initial connection that is formed on mutual interests can become a source for personal and artistic growth, as well as an opportunity for meaningful, and ongoing, developmental relationships to form and take hold. Perhaps even more 
stimulating to a creative artist, the burgeoning mentoring partnership developed in this kind of an arts setting can also be viewed as both an aesthetic reference and a powerful artistic metaphor for life. The significant developmental relationships adopted within the progressive dance and performing arts context uses the artistic process itself to better understand and more clearly pronounce the depth and relevance of such a partnership, and how and why it can be enduring. Furthermore, the process of dance making and performance can directly mirror the mentorship-building process.

Performance Notes \#1: The stage lights are faded to black. As stage lights slowly rise, we see two bodies grab arms and wrists and with a synchronized prep, the bending of knees and the counter pressure of each other's weight pressing upon each other, the first figure lifts the second - with an up and over momentum - that brings the jumping body to a new, secure position. Such begins a motif: a continuous series of bodies making their way onto the stage, lifting and being lifted, preps and jumps helping new bodies enter and progress into and through the stage space.

\section{A Progressive Summer Performing Arts Program: A Site for Mentoring and Developmental Relationships}

A progressive, multifaceted, multidisciplinary arts program - ideally in a diverse setting where complex concepts like "otherness" can be examined, interrogated, and rethought - can offer youth a peak experience that helps build bridges, stimulate relevant conversations, unusual collaborations, and relevant art-making. This type of multidisciplinary program can teach youth how to use the performing arts, with an interdisciplinary mindset, as a tool for creative expression, personal development, and social action. The core values and key creative practices, therefore, incorporate mentoring partnerships, developmental relationships, and a transformational continuum so that all the activities highlight and suggest constructive and optimistic outcomes. These possibilities can also be directly suggested and reflected in the process of making dance and performance pieces. The performances, therefore, can become artistic containers that display individuals of diverse backgrounds working together as a team to creatively traverse across space and time, while simultaneously uncovering and debating complex theories and ideas about society, the human condition, and the process of growing up. This meta-theatrical or meta-dance approach to art-making looks to, and indeed celebrates, all kinds of bodies and movement practices to illustrate how each of us can help (and be helped) as we transition and evolve.

Specifically, a summer school dance theater program held at a college or university site, a future location for increasing intellectual, social, and cultural capital to be actualized, can make use of progressive ideals about the transformative possibilities of the arts to inspire and motivate (to trace the students' pathways into, through, and beyond the program itself). Such a site creates a powerful scaffold for students to imagine their future possibilities, usually in higher education, in the actual (or nearly so) future location. Locating the program in a college or university site is an intentional aspect of the design of the transformational, threshold experience. It is also a uniquely ideal position to initiate deeply meaningful personal connections and ongoing relationships that might produce hugely positive effects. Mentoring expert H. R. Hall (2006) understands that, "adolescent identity is partly constructed by sharing perspectives and personal experiences with others" (p. 17). A multidisciplinary dance program, under the umbrella of progressive performing arts, allows a platform for stories to be shared, for commonalities to be discovered and celebrated without negating the qualities, circumstances, and perspectives that makes all the participants unique or different.

Such diverse gatherings and trusting, creative environments, "inspire us to be bold, to dream big, to affirm the possibility of transformation, to envision radical change" (Keating 2013, p. 10) - and the arts gives us a vehicle to creatively and collaboratively express these new and monumental ideas and possibilities. The vocabulary of dance, as well as physical theatre and multi-disciplinary performing arts, can then turn personal sharings and interactions into relevant performance material. At the same time, the work can be establishing foundations for meaningful mentoring bonds. Dance, theatre, movement, and poetry - and, indeed all progressive performing arts practices - that incorporate a reflective and dialogical process into the experience, have an inherent ability to explore and depict the myriad ways people might move into, through, and beyond any given situation, even the most difficult or treacherous.

Not only can developmental relationships in the arts be a bridge to healthy and stable futures for the current crop of youth participating in these programs, they can become extended bridges that assist the next generation of youth. Many in the performing arts who were substantially mentored and supported along the way have, in turn, figured out their own ways to mentor other youth. Reisman's (1965) "helper-therapy" theory demonstrates how people are actually helping themselves by the act of helping others. Developmental psychologist Erik Erikson (1994) describes such a continuum of mentorship as "generativity", or passing along loving care. This is an investment in paying forward the kindnesses that individuals once received when they were in less stable times of life. In this way, many who were once mentored have gone on to become highly effective mentors. Such a phenomenon is common in the arts where mentored individuals "are more likely to mentor others" (Johnson and Ridley, 2004, p. xi). A summer arts program can establish a built-in mechanism for mentoring relationships to take hold by including undergraduate college students, ideally students who attended the program when they were in high school and therefore have experienced a very similar peak experience, to now take on the role and responsibility of being step-ahead peers to individuals slightly younger than themselves. 
The emergence of a role model within a peak experience in the performing arts and, in this case, a step-ahead role model who is also a performing artist, becomes key to imagining how such ideas become actualized throughout a lifetime. In a dance practice, youth mentors can serve as tangible, in-the-flesh examples of personal, academic, and artistic integrity. The college-aged step-ahead peers mentors can model how to be young artists who are generous, empathetic, and skillful and show that these are worthy qualities to emulate (Rhodes 2002, p. 45). At the same time, they can actively reveal what it takes to transition from high school into college as socially conscious and skillful artists. They demonstrate how as older individuals who have figured out the tricky transition from adolescence into adulthood, they are now regularly using the arts to practice creative self-expression and self-agency and are, themselves, on a committed journey towards self-actualization through higher education.

These college-aged mentors provide consistent behavioral modeling the youth can observe and even attempt to adopt, both artistically and personally. Performing artists themselves, they can provide consistent verbal feedback on the dance-making, performance, along with coaching on how a conscientious arts practice, within higher education, can lead to the evolution of a positive, stable, optimistic individual who is also a generous and passionate artist scholar. Such an intervention is key in turning an isolated peak experience into one that can have both immediate benefits and important, long-term outcomes. Seligman's (2011) "flourishing" model of peak experiences speaks to how transformative experiences can lead to a multifaceted sense of well being, which is the basis for flourishing. In this context, flourishing should not only be indicated in terms of growing talents, or even becoming more self-confident, but also in the ways students might live their lives from that point forward.

In combination, these ideas of progressive performing arts, generativity, transformational learning, and flourishing speak to the metaphorical idea of progress, motion, and movement. Seligman (2011) writes: "the content itself - happiness, flow, meaning, love, gratitude, accomplishment, growth, better relationships — constitutes flourishing. Learning that you can have more of these things is life changing. Glimpsing the vision of a flourishing human future is life changing" (p. 2). These are the kinds of possibilities that can be realized in a progressive multidisciplinary dance program, especially one that brings youth into contact with potential college-aged mentors, as the UCLA summer dance theater program does. Such an overarching goal speaks to an insistence upon turning peak experiences into something meaningful that continues to flow as all participants figure out how to move on to the next part of their lives. How to use the peak experience and have it inform and inspire their life's journeys? It is a ripe opportunity for mentoring partnerships and developmental relationships to take hold and flourish past the event itself.

Performance Notes \#2: As the lights fade up fully, we see how the dancers use momentum and energy, commitment to the paths of other bodies, as everyone appears to be facilitating each other's progress. Their bodies (their appearance, their entering and presencing) immediately indicate a great span of difference - gender, shapes, sizes, shades - as individuals and a group, they are the site of many possible interpretations and interpellations. With the ongoing movement - the synchronized preps, lifts, and hops - the lines and spacing of bodies extends into the downstage areas, spreading out... More and more bodies enter the stage area, sharing weight and lifting each other, if only for a moment.

\section{UCLA Summer High School Dance Theater Intensive Program}

In an overly air conditioned university auditorium on a summer Sunday afternoon, a group of dance and theater instructors await the arrival of their new students - approximately 46 high school students (ages $15-18$ ) from all over the United States, as well as a few international students. Approximately eight college-aged program counselors, who all attended this same summer performing arts program when they were in high school, are walking the newly arrived crop of teenagers down the campus hill where the dorms are located. Upon their arrival, this transformational "journey" will begin. This is the UCLA summer high school dance theater intensive for high school students, taking place in the university's Department of World Arts and Cultures/ Dance.

Together, the teachers, the college-aged counselors, and the high school students coming together represent a wide variety of personal backgrounds, experiences, geographic locations, class, ethnicities, religious affiliations, physical shapes and sizes, sexual orientations, and genders. Like the students and college-aged counselors soon to arrive, the program's directors and faculty are all shades of black, white, and brown, and as creative artists, scholars, and researchers, they represent many dance theater forms, styles, and practices. The key faculty members are an exciting combination of multidisciplinary teaching artists coming from all points on our globe. They believe that a progressive performing arts model can and does change young lives significantly and here they will help the youth learn new dance and arts practices at the same time these youth will help the teachers get to the next place of inspiration in their own artistic and professional journeys. The exchange is reciprocal.

The college-aged program counselors, also functioning as coaches, choreographers and directors, as well as mentors, have returned to work in a program they believed inspired them and changed the trajectories of their lives. They come here now to inspire and guide youth in the performing arts just as they were once inspired and guided a few short years prior. Their overarching goal is to support youth in similar kinds of transformational experiences as they experienced 
when they participated in the program as high schoolers. With a personal connection to the experience at hand, the counselors are in a prime position to directly, and positively, impact the lives of these youth. They are dedicated to helping these adolescent performers identify their personal strengths and greatest potential, locate their power as a group based upon a commitment to trust and generosity, to come in touch with their genuineness as people and performers, and to discover the potential for the arts to transform individuals and society.

For the teen participants, it is a dose of a university experience grounded in an artistic process that promotes social bonding and long-lasting alliances between the students and their peers. Bringing youth into contact with others, all training and developing in a performing arts practice together creates opportunities for being individually and collectively inspired and transformed by the process. At the same time, this away-from-home experience brings youth into direct attention and guidance by teachers, life coaches, sponsors, mentors, as well as directors and choreographers, in new and unexpected ways. Everyone involved, but in particular the college-aged counselors, are dedicated to providing these youth a transformational experience in the arts with profound short-term benefits and very likely ongoing, long-term benefits as well.

By participating in a diverse and inclusive progressive dance and performing arts program, the students - all of whom are on the cusp of adulthood - soon learn to identify, respect, and celebrate their commonality (though not necessarily their sameness) as a group and to better understand their differences. The students learn to use this group knowledge to inspire and inform their new friendships and to situate and initiate their collaborative dance and art-making. They also discover how to better identify the hurdles they have overcome in their lives and share these occurrences with others in a safe and supportive environment. Simultaneously, they look at their future pathways and start to imagine and articulate that which they want and that which stands in their way. Together, as a group, they support each other as they realize they are not alone in their pain or confusion. Together, as a group, they start to use dance and performance as a means to heal the past, to celebrate their current resilience and optimism, and to stare down what they hope to overcome and look truthfully at what it is they hope to achieve from this point forward.

The fears, questions, anxieties, and confusions of the liminal youth are apparent and palpable in every gathering and, as such, become the foundation for the overall mission and goals of the program and its main guiding proposal: Using dance and multidisciplinary arts, how do we best help students of all backgrounds gain the clarity, confidence, and resilience to approach and pass through the threshold of adolescence into adulthood? Keating (2013) reminds us that these threshold experiences demand that we open and stretch our hearts and minds, challenging us to, "re-examine and perhaps change our thinking, our worldviews, and our actions" (p. 11). This openness and ability to change, to evolve and progress, is regularly prioritized, discussed, and made knowable throughout the entire program: each student's personal progress and creative/ artistic potential is the primary focus of the daily dance and movement classes, as well as in the guided social activities, creative writing sessions, acting workshops, creative collaborations, and regular rehearsals - in the dance and rehearsal studios, the dorms, cafeterias, and all the public spaces they occupy throughout the program. Being in the company of and under the guidance of the college-aged counselors ensures that each and every high school student is not only well supervised but also constantly cared for and deeply recognized. Such personal attention sets up the possibility for developmental relationships to begin to develop and become possible to sustain.

The personal and collective changes and developments that occur for the participants are not all circumstantial or accidental, however - they are considered prior to the program and are built in to the proceedings, like a curriculum would be. As part of the creative, artistic, and social processes, the students are regularly and strategically encouraged (and modeled) to think, speak up, trust, share, create, write, reflect, edit, rehearse, connect, and interact mindfully and deeply in order to ensure that important changes in perspectives, world-views, and self-definitions will happen. The multidisciplinary aspect of the program allows for all kinds of artistic gifts and potentials to be stirred, nurtured, and publicly recognized. Moreover, the unusually varied combinations of creative and artistic activities offered and required, asks all participants to rethink their assumptions and expectations and to imagine flexibility and all possibilities, both personally and socially. Dance and the performing arts can offer a generative and creative space to explore, interrogate, and even practice, various ideas about and pathways into adulthood - a chance to consciously imagine and simulate, what theater scholar Meiling Cheng refers to as, a "self-in-becoming" (2002). This changing, liminal self - a being that is ripe to make fresh discoveries and inspiring connections, though ideas that are nearly always abstract in certain ways - needs some direction. Dance practices can help articulate this changing self at the same time it literally and figuratively offers modes of expression and form to this changing self.

The personal discoveries that happen in such a state of flux (and possibility) require guidance and encouragement as well as ongoing opportunities for connection and growth. As cultural theorist Homi Bhabha (1994) describes, "the(se) 'in-between' spaces provide the terrain for elaborating strategies of selfhood - singular or communal - that initiate new signs of identity and innovative sites of collaboration, and contestation, in the act of defining the idea of society itself" (p. 2). Likewise, anthropologist Victor Turner (1967), credited with describing these liminal spaces as being "betwixt and between", understood the inherent complications and possibilities of a space and time that is neither here nor there, 
and as such, a situation and condition that is intrinsically one of "ambiguity and paradox, a confusion of all the customary categories" (p. 96). Turner's and Bhabha's words speak to the potential for a summer performing arts program, especially those where mentoring relationships are originated, to provide guidance to youth at a crucial time in their lives. When designed properly and executed well, such interventions and interactions very well can have monumental and long-lasting impacts.

Still, the UCLA summer program understands that transformation is not a specific location per se, or an end-goal unto itself, but, rather like dance and dancing, it is a fluid state of discovering and growing, moving and stretching and shifting. Therefore, it is a larger goal that is ideally situated in a dance setting, facilitated in a progressive learning environment that is characterized by an inclusive and generous social system of engaged interconnectivity. It is a kind of ensemble dance, created collaboratively that can arise when a shared peak experience establishes meaningful commonality and connection at the same time it celebrates the uniqueness of all the participants. In this particular "dance", no one is the star, or, more accurately, everyone is the star - a creative project, simulating life, that equally recognizes and values everyone's journey and everyone's potential.

This kind of learning, that which could be considered transformational, suggests equality and solidarity, as well as entrusts moving metaphors such as momentum, flow, growth, evolution, and expansion to help represent the experience. Therefore, what happens next for a student, what they do and where they go after the program is finished, is of the greatest concern for a progressive arts educator. Clark and Wilson (1993), building upon the substantive work of adult education scholar Jack Mezirow (1981, 1994, 1997), suggest that transformational learning, with special attention paid to certain sociocultural and historical contexts, can be learning that induces more far-reaching change in the learner than other kinds of learning, especially learning experiences which shape the learner and produce a significant impact, or paradigm shift, which affects the learner's subsequent experiences (p. 76). Likewise, in Merriam, Caffarella, and Baumgartner (2007), the authors state that, "transformational learning is about change, dramatic, fundamental change in the way we see ourselves and the world in which we live" (p. 123). The very special mentor-mentee relationship that the UCLA program initiates is the basis and cornerstone of such a transformative possibility.

Progressive dance and performing arts practices that help inspire an evolving viewpoint of life and life's possibilities, including an emerging recognition of the importance of influential partnerships, recognizes that we are all on a journey in which we impact others as they impact us. Thus, the program understands it is not nearly sufficient to offer a peak, transformational experience to a group of youth from all imaginable backgrounds, encouraging them to dream big and leading them to believe that all is possible, and then sending them on their way to figure out the details and logistics on their own. Rather, the UCLA summer program seeks to connect the single transformative experience of the intensive with numerous follow-up opportunities for students and staff to continue to meet, bond, ally, tutor, coach, train, and collaborate together. Some of these actions and interactions are organic and informal, others are strategic and formalized; regardless, the attempt is made to keep in touch with all of the participants in such a way that no student leaves the UCLA summer theatre intensive program feeling alone or without a step-ahead peer to count on and rely upon, often they have more than one.

Among the ongoing possibilities for developmental relationships to flourish are: one-day dance and theatre intensives held throughout the months following the program; college preparation workshops in which the mentors help the high school youth imagine and prepare for their post-high school pathways, including helping the youth make college visits and prepare college applications and design or rehearse artistic auditions and portfolios; and establishing a private Facebook page where students remain connected in a safe and self-contained space. The groups also often plan and coordinate informal mini-reunions that offer extra opportunities for connection, support, and ongoing community sharing. Additionally, the college-aged program counselors commit to stay in touch and help students for as long as they are needed - most often through to when the high schooler is securely situated into a higher education setting including sometimes becoming first-year college mentors and tutors for the high school students. This connection and continuum enables meaningful developmental relationships to continue to blossom and extend past the summer program, hopefully ensuring that all students will approach and pass through adulthood's threshold feeling supported and sustained.

In combination, these post-program activities and projects are clearly valuable to those students who come from low-income neighborhoods, impacted schools, first-generation family backgrounds, and other possible disadvantages. Many students from these backgrounds only discovered that they could and would like to go on to study in higher education; the program ignites a fire inside of them that enables them to dream of college as an attainable prospect. Of course, these students need the kind of ongoing support, information, training, strategies, and guidance that the mentorship relationships can offer them. However, and maybe less expected, the UCLA summer program has also discovered that these post-program activities are equally beneficial to students from more privileged backgrounds, even those who attend high schools with college preparatory programs and services. Indeed, the full-range of high school students have shared that the UCLA program's diversity and its methods to bond people of different backgrounds, is 
among its most inspirational components; they very often attest that the program's multidisciplinary focus, its multifaceted curriculum, and, importantly, the ability to experience so many complex social and artistic intersections are what makes it such a transformational experience. Likewise, the sequence of post-program activities gives the college-age mentors a chance to practice generativity and participate more fully in the goals of "helper-therapy" adding to their own sense of flourishing, flow, and transformation. The program's commitment to providing a transformational continuum for all participants has shown itself to be a highly effective strategy for developmental relationships to have mutually beneficial long-term impacts.

Performance Notes \#3: More and more bodies enter the stage area, sharing weight and lifting each other, if only for a moment. The expanse of moving bodies edge closer towards the audience, suggesting movements that might lengthen beyond. They are assisting each other with purpose; it is not exactly smooth and effortless, it is not exactly perfection as some "dance" pieces can appear to be, it is clearly work - but it is effective - all of those who enter the stage space are in movement, all assisting and being assisted - a mutual exchange. There is a sense of not knowing exactly where any dancer will end up, nor are they all going in the same direction. Still, the facility of the project is evident. These dance performers, now we see clearly that they are teenagers, successfully assist, and are assisted, to a new place, a different position, a fresh possibility...

\section{This entrance is a metaphor. So, too, is the rest of the performance.}

\section{Conclusion}

Creating opportunities for ongoing support, guidance, and growth for youth after a transformational experience in the performing arts is finished - facilitated by the mentoring and developmental relationships that have been created - has emerged as a beneficial by-product of this model of progressive performing arts training. Such an exciting outcome is evidenced when youth who participated in these programs when they were younger, and who actually benefitted from step-ahead peer mentorship relationships, become committed and skillful mentors to the generations of youth who follow them. The transformative event, therefore, is a pivotal peak experience that sparks ongoing transformations and mentoring that creates both flow and flourishing. The event initially provides intrinsic and fundamental motivation for students to engage with a subject matter they enjoy doing and guides them in transformational learning that ideally has a continuum and further levels of engagement and commitment.

The UCLA Summer Dance Theater program consciously aligns itself with these comprehensive progressive performing arts practices, those that knowingly engage with core values that lead to transformational learning possibilities and, importantly, in a diverse and inclusive setting. Among these methods are finding numerous ways to incorporate engaged social interactions, artistic collaborations, personal bonding and counseling, and even academic coaching that lead to mentoring partnerships to form and developmental relationships to take hold. The formation of these meaningful relationships suggests how a peak artistic (and social) experience might initiate a transformational continuum and intrinsically optimistic outcomes for all student participants. Furthermore, among its most impressive innovations is viscerally demonstrating that which arts educators and mentoring theorists already know to be possible in the arts -long-term transformational possibilities. Though such ideals are often described in the mentoring literature and anecdotally on display in many high quality arts programs, the UCLA Summer Dance Theater program works to track and further articulate these possibilities. Furthermore, the UCLA program believes these benefits can be rooted in the principles of the progressive education movement as it connects and combines with multidisciplinary dance arts pedagogies and practices.

Offering such a comprehensive approach to transformational learning in dance, under the directives of a progressive performing arts methodology, means that hopeful ongoing possibilities can be referred to and represented artistically within the dance and performing arts practice. The results are two-fold: the creation of mentoring and developmental partnerships at the same time that a performance project about the same topic is created and presented. The performance piece described throughout this article, for instance, is an artistic piece that depicts bodies helping other bodies negotiate in-between spaces in order to move forward and beyond. In the context of the UCLA summer dance theater program, this dance-theatre piece, as well as the final performance mirrors the reality of the experience itself, one that has been built upon such concepts and goals as identity exploration, building trust, and engaging in collaboration - all of which are core concepts found within the social bonding occurring and mentoring partnership being developed throughout the program.

The deep and meaningful bonds that can be forged in a progressive dance and arts setting can establish a path for continued transformations and new possibilities to be imagined and initiated, a path full of momentum and flow. The mutually beneficial relationships that develop in such a program - both peer-to-peer alliances and, importantly, the step-ahead mentoring relationships that bring high school youth and college-aged counselors into committed alliances with each other - can become influential developmental relationships, founded upon a mutually transformative event in the arts. This bond can continue to develop and expand well past the peak experience itself. This is an exciting and 
effective relationship model for all progressive performing arts to take on as such a model utilizes transformative pedagogies to both inspire and transform its youth participants at the same time as it creates effective and substantial mentoring partnerships and developmental relationships with college-aged counselors that have a chance of providing both short-term benefits and longer-term impacts and outcomes for both the mentor and the mentee. Together, they can both help and be helped as their journeys unfold, as they work to get from here to there, to move on to bright and stable futures.

\section{References}

Bhabha, H. (1994). The location of culture. New York: Routledge.

Cheng, M. (2002). In other Los Angeleses: Multicentric performance art. Berkeley: University of California Press.

Clark, M. C., \& Wilson, A. L. (1991). "Context and rationality in Mezirow's theory of transformational learning." Adult Education Quarterly, 41(2), 75-91. http://dx.doi.org/10.1177/0001848191041002002

Csíkszentmihályi, M. (1996). Creativity: Flow and the psychology of discovery and invention. New York: Harper Perennial.

Dewey, J. (1897). "My pedagogic creed." School Journal 54:77-80. 1902. The Child and the curriculum. Chicago: University of Chicago Press.

- (1902). The child and the curriculum. Chicago: University of Chicago Press.

. (1916). Democracy and education: An introduction to the philosophy of education. New York: The Macmillan Company.

Erikson, E. (1994). Identity and the life cycle. New York: W. W. Norton.

Giguere, M. (2014). Beginning modern dance (interactive dance series). United States: Human Kinetics (www.humankinetics.com).

Hall, H. R. (2006). Mentoring young men of color. Lanham, Maryland: Rowman \& Littlefield Education.

Hayes, W. (2007). The progressive education movement: Is it still a factor in today's schools? New York: Rowman \& Littlefield Education.

Johnson, W. B., \& Ridley, C. R. (2008). The elements of mentoring. New York: Palgrave Macmillan.

Keating, A. (2013). Transformation now: Toward a post-oppositional politics of change. Urbana, Illinois: University of Illinois Press.

Maslow, A. (1994). Religion, values and peak experiences (NY, Penguin Compass).

Merriam, S. B., Caffarella, R., \& Baumgartner, L. (2007). Learning in adulthood: A comprehensive guide. 3rd ed. San Francisco: Jossey-Bass.

Mezirow, J. (1981). A critical theory of adult learning and education. Adult Education Quarterly, 32(1), 3-24. http://dx.doi.org/10.1177/074171368103200101

- (1994). Understanding transformation theory. Adult Education Quarterly, 44, 222-232. http://dx.doi.org/10.1177/074171369404400403

_. (1997). "Transformative Learning: Theory to Practice." New Directions for Adult and Continuing Education 74 (Summer): 5-12.

Newlove, J. (1993). Laban for actors and dancers. New York: Routledge.

Rhodes, J. E. (2002). Stand by me: The risks and rewards of mentoring today's youth. Cambridge, Massachusetts: Harvard University Press.

Riesman, F. (1965). The helper-therapy principle. Social Work, 10(2), 27-32.

Seligman, M. E. P. (2011). Flourish: A visionary new understanding of happiness and well-being. New York: Free Press.

Simpson, D. J., Jackson, M. J. B., \& Aycock, J. C. (2005). John Dewey and the art of teaching. Thousand Oaks, CA: Sage Publications.

Turner, V. (1967). The forest of symbols: Aspects of Ndembu ritual. Ithaca, N.Y.: Cornell University Press.

\section{$(\mathrm{cc}) \mathrm{BY}$}

This work is licensed under a Creative Commons Attribution 3.0 License. 